\title{
Digitalisasi Manajemen Sistem Dokumen Menggunakan QR Code Generator dan Digital Signature
}

\author{
Muhammad Fabio Armandani \\ Fakultas Ilmu Komputer \\ Program Studi Teknik Informatika \\ Universitas Singaperbangsa Karawang \\ Jl. HS.Ronggo Waluyo, Puseurjaya, Telukjambe Tim., Kabupaten Karawang, Jawa Barat 41361 \\ fabio.armandani17146@student.unsika.ac.id
}

\begin{abstract}
Digitalisasi dokumen merupakan suatu langkah dalam kemampuan serta optimalisasi tempat penyimpanan dan keamanan, pengisian, pencetakan, perekapan data - data sehingga mengurangi penggunaan dokumen hardcopy dan legalitas dokumen tetap utuh. Namun, pada Universitas Singaperbangsa Karawang masih terjadi masalah kehilangan atau perusakan data Mahasiwa yang diakibatkan belum optimalnya sistem digitalisasi dokumen sehingga masih banyak data yang belum tervalidasi. Alasan ini dibuat untuk dapat membuktikan validasi digitalisasi dokumen dengan menerapkan $Q R$ Code dan Digital Signature. Adapun rancangan penelitian ini menggunakan metode SDLC model Prototype. tahapan penelitian ini dibagi menjadi enam, yaitu pemilihan logika kode Hash, aplikasi berbasis web, pembuatan private key dan public key, pengembangan antarmuka aplikasi berbasis mobile, integrasi fungsi yang dibuat dengan aplikasi web, dan integrasi fungsi yang dibuat dengan aplikasi mobile. Hasil penelitian ini diharapkan bisa digunakan dalam pengelolaan sebuah dokumen dalam wujud fisik ke wujud digital menggunakan $Q R$ code.
\end{abstract}

Kata kunci - digitalisasi dokumen, $Q R$ code, dan digital signature

\section{Pendahuluan}

Masa dari ke masa, zaman semakin canggih di era teknologi semakin maju, manusia semakin gencar dalam mengubah proses - proses yang terjadi secara manual menjadi otomatis dengan bantuan komputer untuk memudahkan dalam melakukan suatu pekerjaan. Tak terkecuali pada lembaga perguruan tinggi seperti Universitas. Universitas merupakan sesuatu institusi pembelajaran tinggi serta riset, yang memberikan titel akademis dalam bermacam aspek. Suatu universitas menyediakan pembelajaran sarjana serta pascasarjana. Selaku instansi objektif, Universitas mempunyai peranan untuk menyelenggarakan program pembelajaran akademik ataupun profesional dalam beberapa tertib ilmu pengetahuan. Dalam melaksanakan peranannya, terdapat sekian banyak metode yang berlangsung di dalam intern Universitas. Salah satu cara yang berlangsung ialah pembuatan digitalisasi dokumen Mahasiswa. Digitalisasi ialah cara transformasi dari seluruh wujud arsip tercetak ataupun lainnya ke dalam penyajian wujud digital [1].

Digitalisasi dokumen diperlukan untuk memperoleh kemampuan serta optimalisasi dalam banyak perihal, antara lain kemampuan serta optimalisasi tempat penyimpanan, keamanan dari bermacam bentuk marabahaya, untuk tingkatkan resolusi, gambar serta file agar konstan. Perubahan digitalisasi dokumen dari manual menjadi terkomputerisasi memiliki banyak dampak positif seperti kemudahan dalam pengisian, pencetakan, perekapan data - data sehingga mengurangi penggunaan dokumen hardcopy dan legalitas dokumen utuh. Digitalisasi dokumen diharapkan bisa jadi pengganti pengamanan arsip pada periode panjang [2]. Sementara menurut Sugiharto menyatakan kalau cara digitalisasi dari wujud kertas memerlukan perlengkapan flatbed scanner ataupun kamera set pada meja flatbed [3].

Hakim dalam tulisannya berpendapat bahwa, dokumen mempunyai kedudukan berarti dalam pengurusan institusi ataupun badan [4]. Dokumen jadi salah satu materi pendapat arahan guna mengambil ketetapan. Searah dengan kemajuan yang berlangsung informasi tidak cuma ditaruh dalam bentuk tercetak, tapi ditaruh dalam bentuk digital. Pengurusan arsip digital ialah upaya yang dicoba institusi guna menyuguhkan layanan yang sesusia dengan situasi dikala ini. Namun, permasalahan validasi data menjadi poin yang sangat penting, mengingat masalah kehilangan data atau perusakan data digitalisasi dokumen baik secara disengaja maupun tidak sengaja dapat terjadi. Termasuk pada Universitas Singaperbangsa Karawang masih banyak yang belum divalidasi sehingga banyak hambatan dalam perkuliahan yang tersimpan di dalam basis data dengan data digitalisasi dokumen Mahasiswa yang berupa dokumen cetak.

Banyak teknologi yang dapat digunakan dalam melakukan penerapan Rekayasa Perangkat Lunak, salah satunya adalah teknologi $Q R$ (Quick Response) Code. $Q R$ Code adalah salah satu jenis kode matriks yang memungkinkan isinya dapat diterjemahkan dengan kecepatan tinggi [5]. QR Code yang sering ditemui dan dilihat pada umumnya berbentuk persegi kecil yang sering berada pada kemasan barang elektronik, kemasan makanan, dan lain-lain. Data yang dirahasiakan oleh $Q R$ Code ini bisa berbentuk URL, pesan, gambar, nomor telepon, pesan SMS, Vcard, atau teks apapun [6]. QR Code mampu mengoreksi kesalahan dan pengembalian data dalam artikulasi isyarat bila QR Code kotor ataupun cacat. Terus menjadi besar tingkatan emendasi kekeliruan pada QR Code hingga terus menjadi besar pula tipe yang terdapat pada QR Code itu. Ada beberapa factor yang perlu ditimbangkan dalam menetapkan tingkatan dari $Q R$ Code, yaitu faktior lokasi dan lingkungan. Level $\mathrm{Q}$ dan $\mathrm{H}$ 
sangat baik digunakan pada proyek pabrik yang tidak bersih, namun tingkat level $Q R$ Code L baik digunakan ditempat yang tidak kotor. Tingkatan yang paling selalu digunankan yakni tingkatan $\mathrm{M}$ dengan proyeksi perbaikan berkisar $15 \%$.

Adapun untuk memastikan data tersebut adalah data yang sebenarnya, maka dapat digunakan dengan Digital Signature. Digital Signature sehingga pihak - pihak yang tidak memiliki kewenangan, tidak dapat mengubah isi informasi yang telah disimpan di dalam $Q R$ Code tersebut. Sedangkan menurut Warasart \& Kuacharoen bahwa Digital Signature memiliki sebuah pola yang bergantung terhadap pesan yang akan ditandai dan menggunakan beberapa informasi unik yang merujuk pada si pembuat pesan [7]. Dalam prakteknya bahwa Digital Signature memanfaatkan teknologi Kriptografi Asimetri / Kunci Publik. Cara pembuatan serta pengecekan tanda- tangan ini mengaitkan beberapa metode kriptografi semacam hashing serta enkripsi asimetris. Peranan hash ini menciptakan angka hash ataupun message digest dari sesuatu catatan. Inti catatan ini berperan selaku selidik jemari dari sesuatu catatan akibatnya tiap catatan yang berlainan akan menciptakan message digest yang berlainan pula.

Software Development Life Cycle (SDLC) adalah tahapan-tahapan atau proses yang dilakukan untuk sebuah proyek atau suatu penelitian yang menghasilkan suatu produk bagi suatu organisasi. SDLC ini terdiri dari rencana yang rinci untuk menjelaskan cara melakukan pengembangan, pemeliharaan, mengubah atau untuk meningkatkan spesifikasi dari suatu produk yang menjadi proyek atau penelitian. Tujuan dari SDLC, yaitu untuk menghasilkan suatu produk yang berkualitas untk memenuhi harapan dari client suatu perusahaan serta menentukan pencapaian dalam perkiraan waktu dan biaya dari proyek atau penelitian yang dikerjakan.

Berdasarkan uraian diatas, digitalisasi dokumen telah jadi keharusan dalam pengurusan akta. Dalam pengurusan arsip digital, cara digitalisasi tidak sekedarhanya melaksanakan pemindaian pada arsip namun pula wajib dicermati cara pencarian informasi yang dengan gampang bisa dicoba dan cara penyaluran yang bisa dengan gampang tersebar dengan kilat. Dengan tersebarnya arsip ini pastinya butuh terdapatnya catatan cara buat membenarkan kalau arsip digital yang tersebar itu sedang selaras dengan aslinya tanpa terdapat pergantian ataupun catatan yang dicoba pihak lain. Kejelasan kalau arsip digital ini masih cocok dengan yang asli bisa dicoba dengan pemberian digital signature itu.

Tujuan dalam penelitian ini, yaitu merandang dan membuat satu sistem yang bisa membuktikan validasi digitalisasi dokumen dengan menerapkan $Q R$ Code dan Digital Signature. Digital Signature dibuat untuk menyimpan informasi mengenai digitalisasi dokumen pada saat pertama kali dicetak, dilakukan enkripsi terlebih dahulu agar tidak dapat diubah oleh pihak yang tidak berwenang, lalu hasil enkripsi akan disimpan pada $Q R$ Code.

\section{STUDI LITERATUR}

\section{A. Kode QR (Quick Response Code)}

Kode QR atau yang lebih dikenal dengan sebutan $Q R$ Code atau kode batang ini adalah jenis barcode yang berbentuk dua dimensi, yang dikembangkan oleh salah satu anak perusahaan pembuat mobil yang sudah terkenal di dunia yaitu Toyota. Perusahaan yang mengembangkan $Q R$ Code ini adalah Denso Wave, yaitu anak perusahaan Toyota asal jepang yang berdiri pada tahun 1994. Tujuan utama dikembangkanya $Q R$ Code ini adalah untuk mempermudah dan mempercepat penyampaian suatu informasi agar mendapatkan tanggapan secara cepat juga.

\section{B. Digital Signature}

Digital Signature memiliki sebuah pola yang bergantung terhadap pesan yang akan ditandai dan menggunakan beberapa informasi unik yang merujuk pada si pembuat pesan [8). Cara pembuatan serta pengecekan tandatangan ini mengaitkan beberapa metode kriptografi semacam hashing serta enkripsi asimetris. Guna hash ini menciptakan angka hash ataupun message digest dari sesuatu catatan. Inti catatan ini berperan selaku periksa jemari dari sesuatu catatan alhasil tiap catatan yang berlainan hendak menciptakan message digest yang berlainan pula.

C. Metodologi SDLC (Software Development Life Cycle)

Software Development Life Cycle (SDLC) adalah tahapan-tahapan atau proses yang dilakukan untuk sebuah proyek atau suatu penelitian yang menghasilkan suatu produk bagi suatu organisasi. SDLC ini terdiri dari rencana yang rinci untuk menjelaskan cara melakukan pengembangan, pemeliharaan, mengubah atau untuk meningkatkan spesifikasi dari suatu produk yang menjadi proyek atau penelitian.

\section{SDLC Model Prototype}

Pada metodologi SDLC mempunyai berbagai model life cycle untuk pengembangan suatu produk yang dirancang dan di pantau selama proses pengembangan dari suatu produk yang sedang di rancang. Proses ini seringkali disebut sebagai Software Development Process Models (SDPM). Setiap model pada SDLC memiliki serangkaian tahapan yang berbeda untuk setiap model nya untuk memastikan keberhasilan dalam proses pengembangan suatu produk atau perangkat lunak.

\section{E. Exiftool}

Exiftool yakni aplikasi open source yang berfungsi untuk membaca, menulis, dan melakukan manipulasi terhadap metadata dari file seperti audio, video, dokumen dan lain sebagainya [9]. Aplikasi ini tersedia baik dalam library untuk bahasa pemrograman Perl maupun sebagai aplikasi yang dapat diakses melalui command line. 


\section{METODE PENELITIAN}

Objek pada penelitian ini adalah Universitas Singaperbangsa Karawang (UNSIKA). Pada penelitian ini yang akan diteliti adalah dokumen - dokumen Mahasiswa di Fakultas Ilmu Komputer UNSIKA. metodologi yang akan digunakan adalah menggunakan SDLC dengan model Prototype serta menggunakan Digital Signature untuk mengumpulkan data - data yang diperlukan. Metode ini dipilih karena dapat membantu dalam validasi data yang terbentuk dalam $Q R$ Code secara mudah dan langsung tervalidasi secara otomatis di sistem akademik UNSIKA.

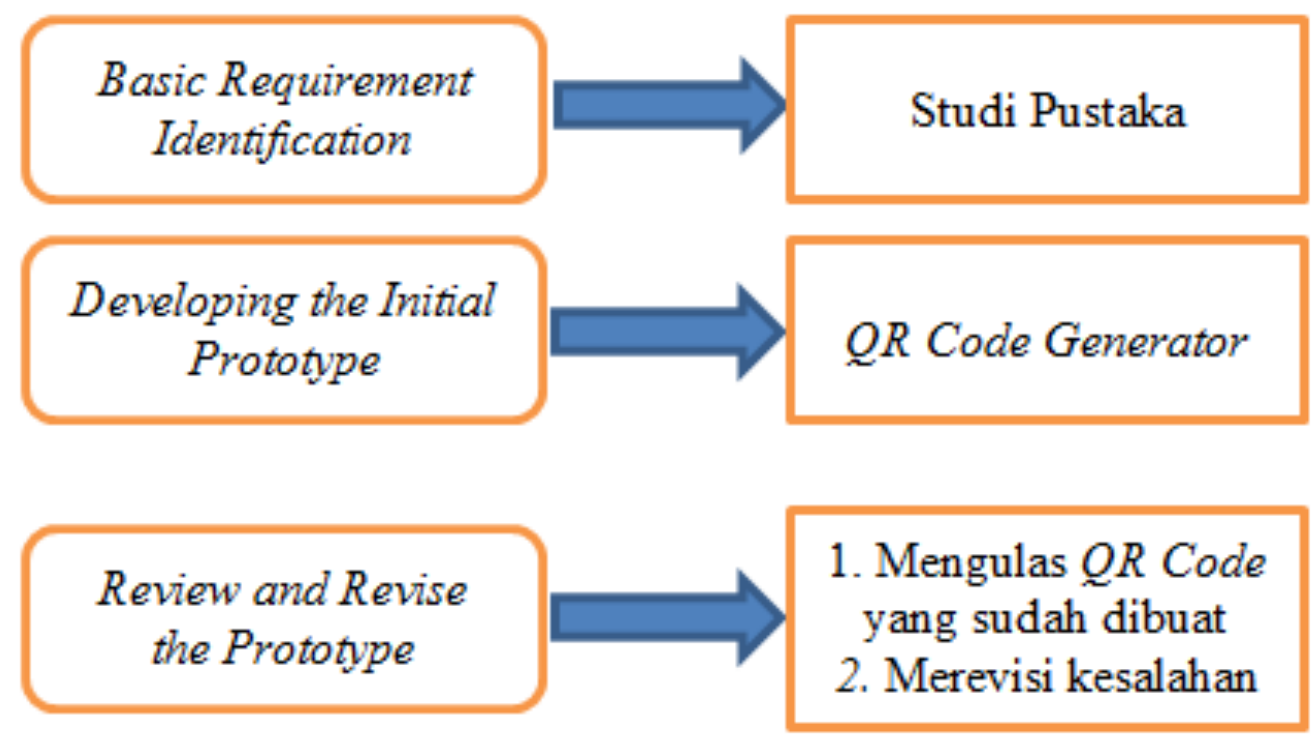

Gambar 1 Tahapan Pengembangan SDLC Model Prototype

Pada metode SDLC model Prototype ada tahapan - tahapan dalam proses pengerjaannya dalam merancang dan membuat QR Code berdasarkan kebutuhan di Fakultas di Universitas Singaperbangsa Karawang yaitu Basic Requirement Identification, Developing the Initial Protoype, Review and Revise the Protoype. Adapun alur perancangan sistem dalam penelitian ini terdiri dari:

1. Proses pemberian $Q R$ Code dan Digital Signature

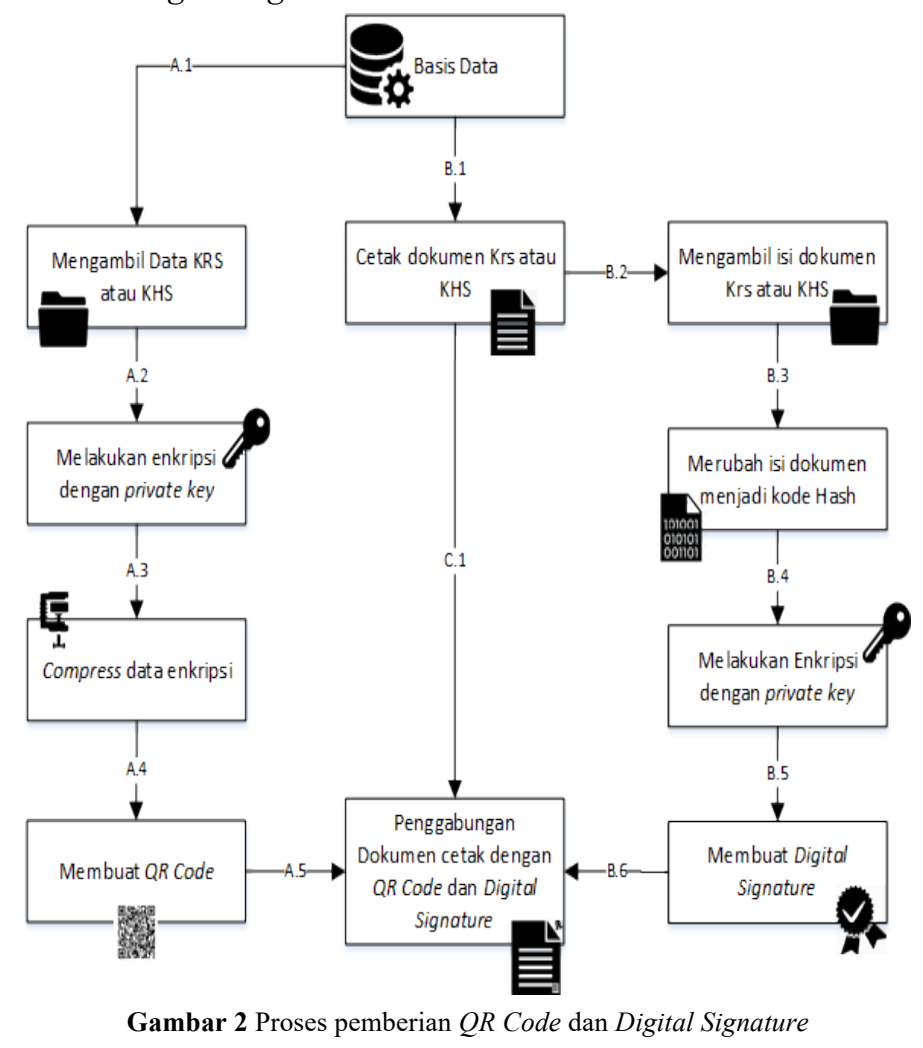

Pada tahapan diatas dibagi menjadi tiga tahapan yang harus dilakukan yaitu tahapan pertama merupakan tahapan untuk membuat $Q R$ Code bagi dokumen, tahapan kedua merupakan tahapan membuat Digital Signature bagi dokumen Mahasiswa dan Tahapan ketiga merupakan tahapan untuk memberikan QR Code dan Digital Signature yang telah dibuat pada dokumen digital Mahasiswa.

2. Proses validasi dokumen Mahasiswa

a. Proses validasi dokumen Digital 


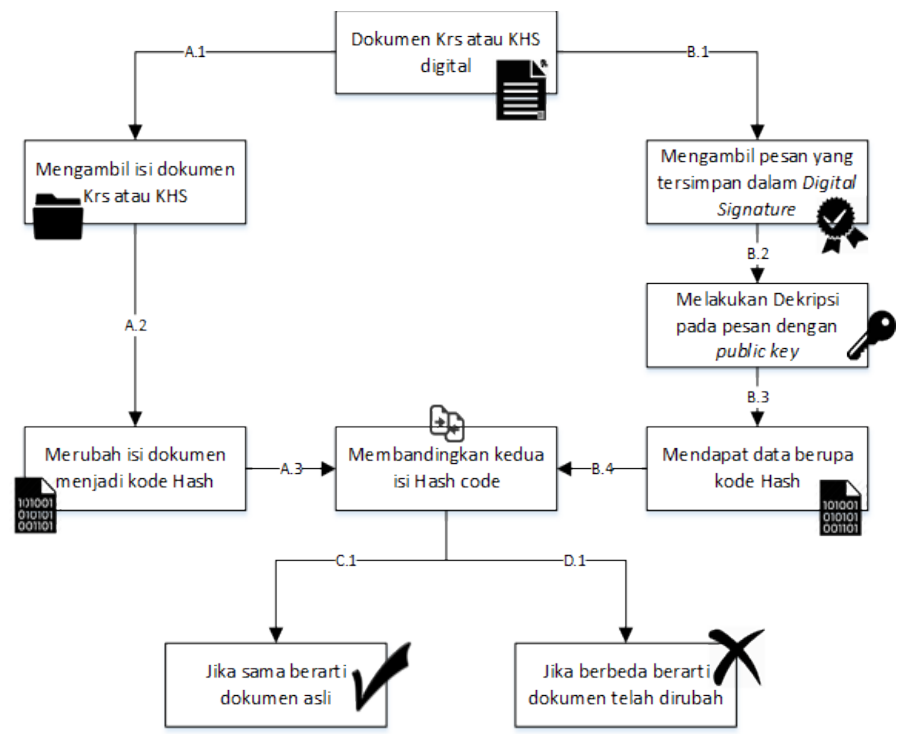

Gambar 3. Proses validasi dokumen Digital

Pada tahapan diatas dibagi menjadi tiga tahapan yang harus dilakukan yaitu tahap pertama merupakan tahapan untuk membuat kode Hash dari dokumen digital Mahasiswa, Tahapan kedua merupakan tahapan untuk mengambil kode Hash yang disimpan di dalam Digital Signature dokumen digital Mahasiswa.

b. Proses validasi dokumen cetak

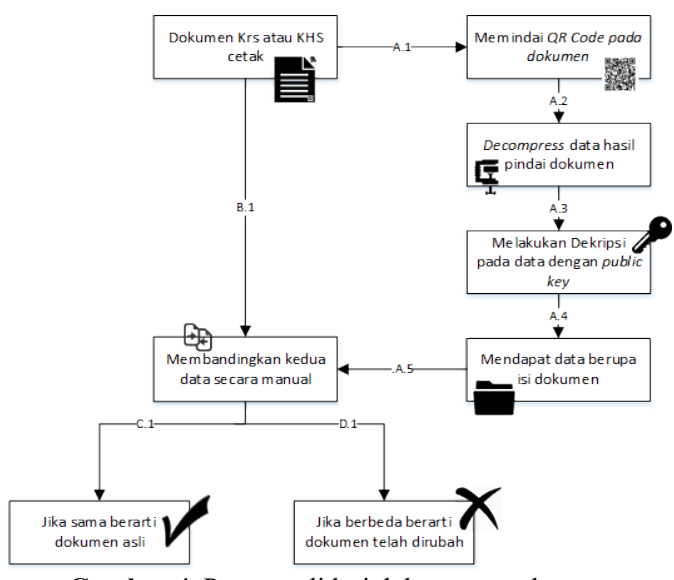

Gambar 4. Proses validasi dokumen cetak

Penelitian ini menerapkan pembangunan sistem dengan beberapa tahapan. Konsep utama pembangunan sistem ini yakni pemberian jalan kegiatan totalitas jadi sebagian langkah yang silih berhubungan [10].

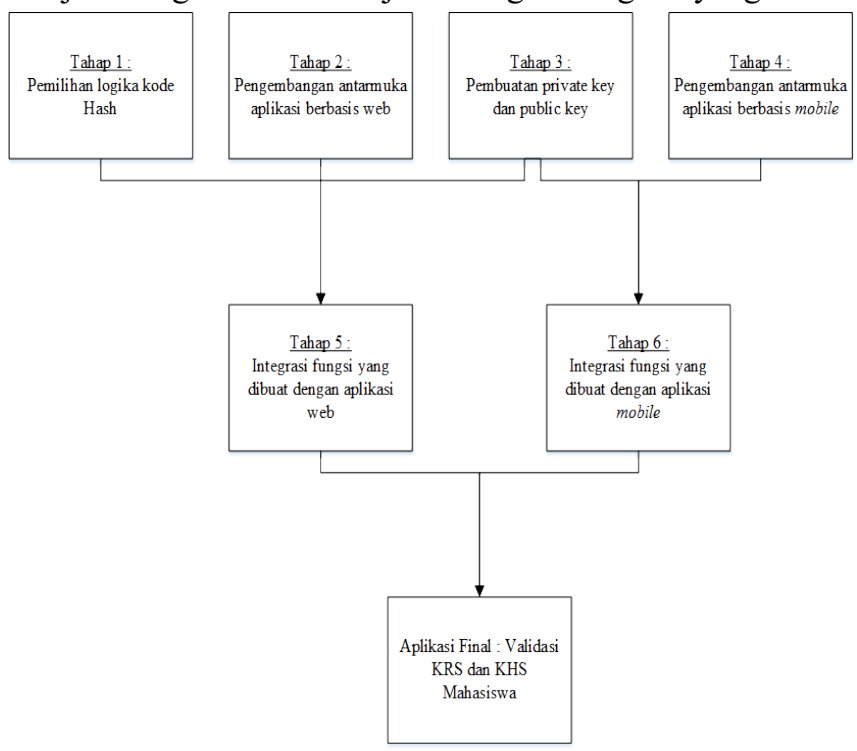

Gambar 4. Proses validasi dokumen cetak

IV. HASIL DAN PEMBahasan 
Hasil penelitian yang dilakukan oleh penulis, adalah untuk memanajemen sebuah dokumen dalam bentuk fisik ke dalam bentuk digital dengan menggunakan $Q R$ code. Untuk mempermudah dalam proses pembuatan $Q R$ code penulis menggunakan $Q R$ code generator sebagai aplikasi berbasis web untuk merubah dokumen menjadi $Q R$ code yang nantinya dapat mempermudah orang yang akan mencari jurnal,buku atau dokumen lainya tidak harus dalam bentuk fisik buku tersebut melainkan hanya dalam bentuk e-book saja dengan men scan $Q R$ code yang telah disediakan.

\section{Basic Requirement Identification}

Kebutuhan dasar dalam penelitian ini adalah mengumpulkan terlebih dahulu studi pustaka atau sumber bacaan dari buku-buku, sebab kebutuhan ini dimulai dengan melakukan identifikasi kebutuhan terhadap model yang akan dibuat.

\begin{tabular}{|c|c|c|c|}
\hline (9) tran2009.pdf & 11/11/2020 1:35 AM & Chrome HTML Do... & $326 \mathrm{~KB}$ \\
\hline (9) koryachko2017.pdf & 11/11/2020 1:49 AM & Chrome HTML Do... & $4,434 \mathrm{~KB}$ \\
\hline gulati2013.pdf & 11/11/2020 1:38 AM & Chrome HTML Do... & $255 \mathrm{~KB}$ \\
\hline (9) ghafouri2020.pdf & 11/11/2020 2:07 AM & Chrome HTML Do... & $6,563 \mathrm{~KB}$ \\
\hline gelenbe2020.pdf & $11 / 11 / 20202: 01 \mathrm{AM}$ & Chrome HTML Do... & $4,217 \mathrm{~KB}$ \\
\hline (9) ding2011.pdf & $11 / 11 / 20201: 40$ AM & Chrome HTML Do... & $404 \mathrm{~KB}$ \\
\hline C bhushan2014.pdf & 11/11/2020 1:48 AM & Chrome HTML Do... & $454 \mathrm{~KB}$ \\
\hline (9) berliner2017.pdf & 11/11/2020 1:54 AM & Chrome HTML Do... & $941 \mathrm{~KB}$ \\
\hline (9) asokan2010.pdf & 11/11/2020 1:37 AM & Chrome HTML Do... & $203 \mathrm{~KB}$ \\
\hline (9) adhyapok2020.pdf & 11/11/2020 1:51 AM & Chrome HTML Do... & $1,083 \mathrm{~KB}$ \\
\hline (C) 12214-37380-1-PB.pdf & 11/11/2020 1:26 AM & Chrome HTML Do... & $498 \mathrm{~KB}$ \\
\hline C 3200-8957-1-PB.pdf & 11/11/2020 1:17 AM & Chrome HTML Do... & $255 \mathrm{~KB}$ \\
\hline C) 54-219-1-PB.pdf & 11/11/2020 1:24 AM & Chrome HTML Do... & $829 \mathrm{~KB}$ \\
\hline (9) 38-Article Text-392-1-10-20200823.pdf & 11/11/2020 1:24 AM & Chrome HTML Do... & $329 \mathrm{~KB}$ \\
\hline C) 34-131-Article.pdf & 11/11/2020 1:43 AM & Chrome HTML Do... & $404 \mathrm{~KB}$ \\
\hline $10 f 606 f 0 c 70 d 5 d 08858 \mathrm{bff} 8 \mathrm{a} 3 \mathrm{~b} 830 \mathrm{a} 77 . \mathrm{df}$ & 11/11/2020 2:05 AM & Chrome HTML Do... & $374 \mathrm{~KB}$ \\
\hline
\end{tabular}

Gambar 5. Contoh dokumen

Dokumen yang akan di manage dan di ubah ke dalam bentuk $Q R$ code agar nantinya para peminjam buka yang data ke perpustakaan yang akan meminjam sebuah jurnal atau buku-nuku pengetahuan tidak perlu lagi mencari buku tersebut dengan susah paryah hanya tinggal menscan $Q R$ code yang telah tersedia agar dapat mendapatkan buku atau jurnal yang dibutuhkan. Sebab QR ataupun Quick Response bisa menterjemahkan dengan kilat konten ataupun informasi yang ditaruh di dalamnya [11].

\section{Developing Initial Prototype}

Proses pembuatan $Q R$ code pada dokumen-dokumen yang telah dikumpulkan sebelumnya, dibuat menggunkan $Q R$ code generator, dimana dengan menggunakan $Q R$ code generator tersebut maka file dokumen dapat dibuat da desain sesuai keinginan serta $Q R$ code yang di scan akan langsung menuju pada dokumen yang di inginkan sesuai dengan topik dari pembahasan dan judul dari $Q R$ code yang di pindai. Di bagian $\mathrm{QR}$ Code Generator dibutuhkan koneksi ke database supaya data bisa ditaruh.
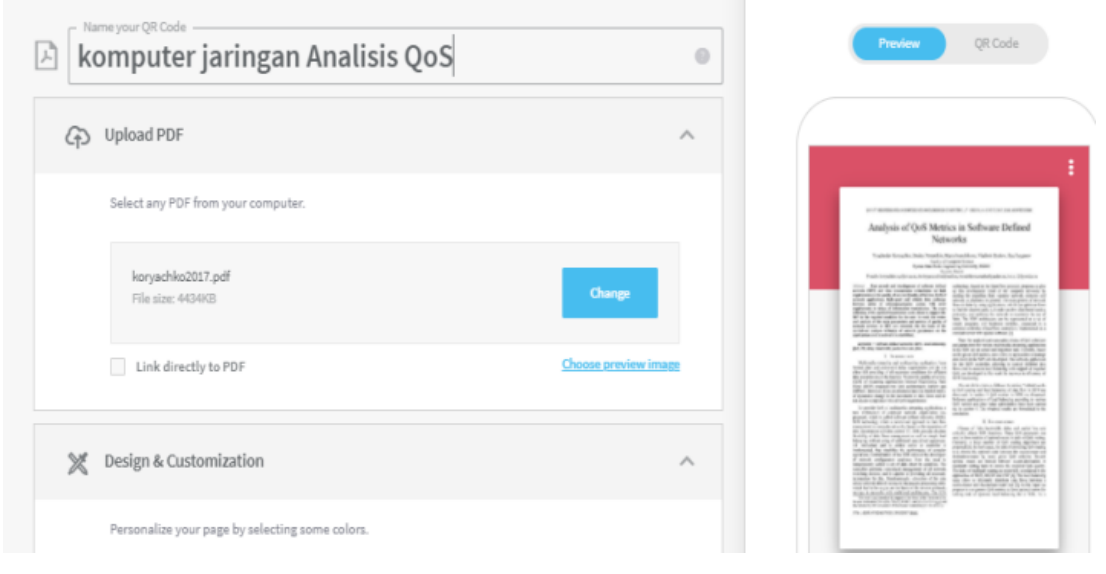

Gambar 6. pembuatan dokumen ke dalam QR code

Sebelum $Q R$ code dibuat penulis dapat terlebih dahulu melihat preview dari hasil pemindaian yang akan terjadi jika $Q R$ code di pindai. Setelah selesai dengan proses pembuatanya maka hasil dari pembuatan $Q R$ code. 


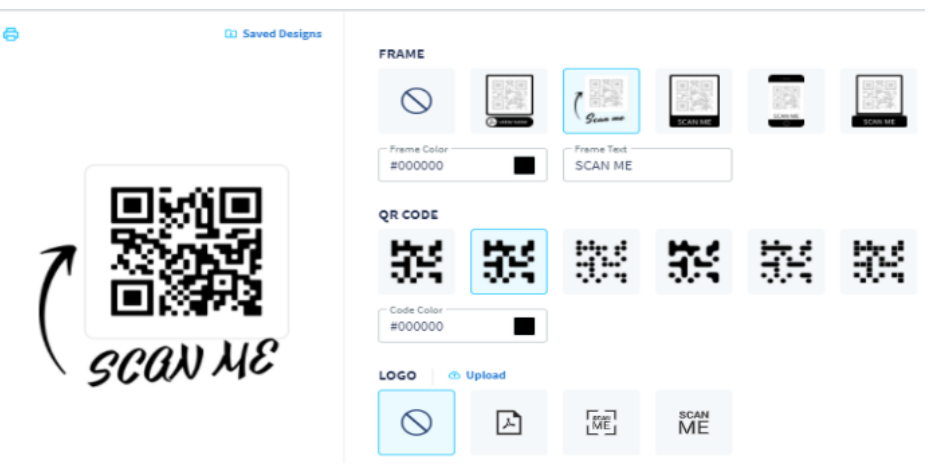

Gambar 7. Hasil $Q R$ Code Yang Dibuat

$Q R$ code diaats telah selesai di buat dan telah siap untuk dipindai untuk menampilkan file dokumen yang terdapat pada $Q R$ code tersebut.

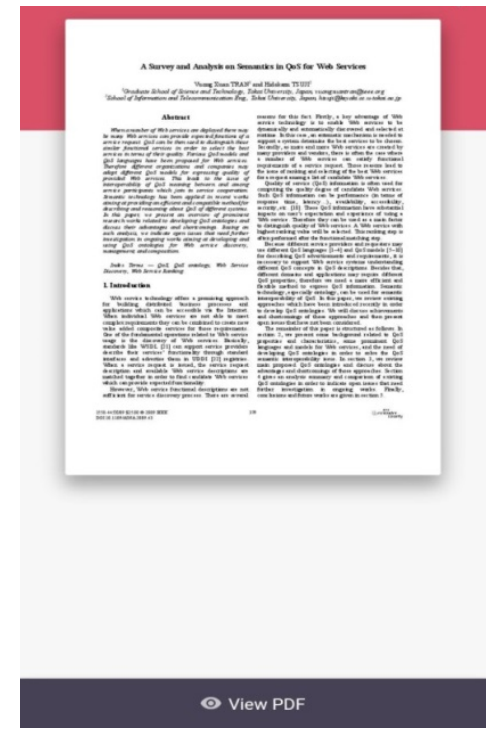

Gambar 8. Hasil Pemindaian $Q R$ Code

Hasil pemindaian $Q R$ code di atas, $Q R$ code akan menampilkan dokumen yang ada di dalamnya, jadi seseorang yang memindai $Q R$ code tersebut akan langsung di arahkan menuju dokumen yang mereka pindai, jika ingin melihat isi jurnal atau dokumen yang di pindai lebih banyak lagi maka hanya tinggal menekan tombol view pdf maka dokumen akan otomatis ter download pada ponsel pengguna.

\begin{tabular}{|c|c|c|}
\hline Name & Date modified & Type \\
\hline Jurnal Kesehatan & 7/18/2021 11:40 AM & File folder \\
\hline Jurnal Otomotif & 7/18/2021 11:40 AM & File folder \\
\hline Jurnal teknologi jaringan komputer & 7/18/2021 11:44 AM & File folder \\
\hline
\end{tabular}

Gambar 9. Manajemen Menggunakan Folder Untuk Memisahkan Setiap Dokumen

Penulis menggunakan folder dalam memanajemen dokumen-dokumen yang telah ubah menjadi $Q R$ code agar memudahkan jika penggunaan menginginkan topik yang sesuai dengan kebutuhanya, agar $Q R$ code yang dibuat tidak teracampur dengan topik pembahasan lainya.

\section{Review and Revise Enhance The Prototype}

Pada tahapan terakhir dari penelitian ini penulis mengulas kembali dari $Q R$ code yang telah dibuat sebelumnya, karena pada tahap ini terdapat 2 tahapan yaitu sebegai berikut :

1. $\quad$ Mengulas $Q R$ code yang telah dibuat

Pada $Q R$ code yang telah dibuat sudah sesuai dengan apa yang dibutuhkan dan konsep yang diterapkan yaitu, jika $Q R$ code di pindai oleh pengguna maka akan mengarah pada dokumen yang di inginkan, dan telah di manage dengan menggunakan folder sesaui dengan topik masing-masing dokumen.

2. Revisi dan peningkatan

Pada penelitian tidak terdapat revisi pada $Q R$ code yang telah dibuat, karena tidak terjadi error atau cacat pada 
QR code pada saat proses pemindaian.

\section{KESIMPULAN}

Berdasarkan penelitian yang telah dilakukan oleh penulis, maka dapat ditarik kesimpulan yaitu dalam melakukan pencarian dokumen dalam bentuk digital pada sebuah perpustakaan dapat dilakukan dengan cara memindai $Q R$ code yang sudah di manajemen pada folder yang sudah dibuat, orang yang membutuhkan dokumen hanya perlu memindai dokumen dengan topik yang dibutuhkan agar dokumen tersebut dapat langsung terlihat pada ponsel orang tersebut dan dapat langsung di download, Dokumen dalam bentuk digital akan lebih memudahkan pengguna karena jika dokumen dalam bentuk fisik sedang tidak ada maka pengguna dapat memindai $Q R$ code yang suda di sediakan agar langsung bisa mengunduh dokumen tersebut kedalam ponselnya dan Dokumen dalam bentuk fisik di ubah kedalam bentuk digital dengan menggunakan $Q R$ code karena dapat digunakan dengan fleksibel dimana saja tanpa harus meminjam buku dalam bentuk fisi dan lebih praktis untuk digunakan.

Adapun saran dari hasil temuan penelitian ini yaitu manajemen dokemen dalam bentuk digital ini sebaiknya dapat berbasis website karena dengan website orang yang akan mencari buku tersebut tidak perlu datanb lagi ke tempat untuk memindai $Q R$ code. Hanya perlu masuk ke website penyedia dokumen atau buku digital tersebut lalu memilih topik yang sesuai dengan ke ingin dan dapat meindai $Q R$ code dimanapun pengguna tersebut berada.

\section{DAFTAR PUSTAA}

[1] Mustofa, "Upaya Pelayanan Di Era Digital Natives,” J. Perpust. Univ. Airlangga, vol. 8, no. 2, pp. 61-68, 2018, [Online]. Available: https://e-journal.unair.ac.id/JPERPUS/article/view/20686.

[2] Wirajaya, Asep Yudha, dkk. 2016. Konservasi serta Pelestarian Naskah- naskah Nusantara di Surakarta selaku Usaha Pengamanan Peninggalan Bangsa. Etnografi: Harian Riset Adat Etnik. Pangkal http: atau atau jurnalfib. uns. ac. id atau index. php atau etnografi atau article atau view atau 322 atau 114.

[3] Sugiharto, Dhani. 2010. Pengamanan Data Akta atau Arsip di Masa Teknologi Digital. Harian Pusat Pemilihan serta Informasi- LIPI. ANRI: Jakarta. Pangkal\&lt;http: atau atau pdii. lipi. go. id atau baca atau index. php atau baca atau ari cle atau view atau 96 . Diunduh[05 April 2021].

[4] Hakim, H. A. 2015. OMEKA: Aplikasi Pengelola Arsip Digital. Jupiter, Vol. XIV, Nomor. 2, 31 - 37.

[5] Rouillard, J. 2008. Contextual QR Codes. International Multi- Conference on Computing in the Garis besar Information Technology., $1-6$.

[6] Singhal, A.,\&amp; Pavithr, R. 2015. Degree Certificate Authentication using QR Code and Ponsel pintar. International Journal of Computer Applications, 120( 16), 38- 43.

[7] Warasart, Meter.,\&amp; Kuacharoen, P. 2012. Paper- based Document Authentication using Digital Signature and QR Code. 4TH International Conference on Computer Engineering and Technology( ICCET), 1- 5.

[8] Warasart, Meter.,\&amp; Kuacharoen, P.2012. Paper- based Document Authentication using Digital Signature and QR Code. 4TH International Conference on Computer Engineering and Technology( ICCET), 1- 5.

[9] Exiftool. (2003). Exiftool. Retrieved July 25, 2016, from http: atau atau www. sno. phy. queensu. ca atau phil atau exiftool atau

[10] Hidayat, E. Y.,\&amp; Firdausillah, F. 2014. Sistem Legalisir Scan Ijasah Online. Universitas Dian Nuswantoro: Semarang.

[11] M. Amrou, A. Boulmakoul, H. Badir, and A. Lbath. 2019. A scalable real- time tracking and monitoring architecture for logistics and transport in RoRo terminals. Procedia Comput. Sci., vol. 151, pp. 218-225. 